\section{Winged messenger set to follow ancient mariner to Mercury}

Tony Reichhardt, Washington

Scientists and engineers will hold their breath next week as NASA prepares to shoot a spacecraft towards one of the last unexplored planets of our Solar System - Mercury.

The Mercury mission had significant challenges to overcome before reaching the launch pad. For example, it had to be designed to withstand temperatures of more than $400{ }^{\circ} \mathrm{C}$ and to perform a tricky orbital insertion. At the time it was approved in 2001, NASA officials called it the most complex Discovery-class planetary mission they had ever attempted. Discovery missions are designed to have the relatively low cost of less than US\$400 million.

The Mercury Surface, Space Environment, Geochemistry and Ranging (MESSENGER) spacecraft is set to leave Cape Canaveral, Florida, on 2 August, with launch windows every day until 14 August. It should arrive at Mercury in March 2011.

The only other visitor to Mercury has been Mariner 10, which mapped $45 \%$ of the planet's rocky, cratered surface in 1974 and 1975. Mariner left key questions unanswered, such as whether the surface rocks are volcanic in origin, and why Earth and Mercury have global magnetic fields, but Mars and Venus do not. A suite of seven instruments onboard MESSENGER, including X-ray, $\gamma$-ray and infrared spectrometers, will try to come up with answers, while cameras will map the entire surface at high resolution.

Getting MESSENGER into orbit around a planet so small and so close to the Sun will not be easy. In fact, it was considered impractical using current rockets until a mission designer in the 1980 s found a way to slow down a spacecraft using a complicated series of loops around Venus and Mercury.

Even then the project nearly never took off. Last year NASA threatened to terminate it for running $\$ 26$ million over its agreed cost limit. The agency's Space Science Advisory Committee saved the project by advising NASA to spend the extra money, even if it meant delaying other planetary missions.

If successful, it will be a relief for mission designers at the Johns Hopkins University Applied Physics Laboratory in Laurel, Maryland. The lab's last Discovery spacecraft built for NASA - the Comet Nucleus Tour (CONTOUR) - failed shortly after leaving Earth in 2002. http://messenger.jhuapl.edu

\title{
Russian bid to drill Antarctic lake gets chilly response
}

\section{Jim Giles}

Russian researchers are preparing to drill into an underground lake in Antarctica despite concerns from fellow polar scientists that the plan may be too hasty.

The Russian team will begin drilling down to Lake Vostok, which lies nearly 4,000 metres below the surface and is thought to have been isolated for 20 million years, in December.

But experts say that the team's equipment has not been properly tested and could contaminate the potentially unique ecosystems that inhabit Vostok's 5,400 cubic kilometres of water.

"The lake is too valuable to experiment with," warns Cynan Ellis-Evans, a microbiologist at the British Antarctic Survey in Cambridge, UK. Researchers hope that any organisms found in the lake could shed light on both early life on Earth and the possibility of life existing on other icy planets.

The Russian plans are likely to spark heated debate at a meeting of the Scientific Committee on Antarctic Research, held in Bremen, Germany, on 25-31 July. Many of the Antarctic scientists contacted by Nature before the meeting suggested that the researchers should drill into one of the more than 100 other subglacial lakes instead - both to test the equipment and to study the ecosystems.

The other lakes may not be as old as Vostok, but their smaller size may ease sampling of their waters, says Martin Siegert, a glaciologist at the University of Bristol, UK. "There is huge kudos associated with the first exploration of Vostok," he adds. "It's very difficult to get another lake on the agenda."

The Russian team, led by Valery Lukin of the Arctic and Antarctic Research Institute in St Petersburg, plans to extend a 3.5-kilometredeep borehole that already exists at the Vostok station. Work on that hole stopped in 1998 when it was realized that unsterilized drilling equipment was just 130 metres from the lake's surface. The Russians hope to break through to the lake in 2006-07.

Water from the lake, which is at high pressure, should move up into the borehole and freeze. Lukin's team will then drill into and extract this frozen water. The group says that its drill is designed to prevent any surface contamination from entering the lake.

But polar scientists say that the Russian plans, while reasonable on paper, need to be tested. They point out that the borehole contains about 60 cubic metres of kerosene, added to prevent the drill freezing, which is contaminated with surface microbes. And the lake water, which is at about 400 atmospheres, could explode into the borehole. "It will be like drilling through the cork of a champagne bottle," says Ellis-Evans.

Experts say that the Russian researchers have addressed some of the international community's concerns. But "they have dealt poorly with the contamination issues", says Jean-Robert Petit, an Earth scientist at the Laboratory of Glaciology and Environmental Geophysics near Grenoble, France, and a member of an international team developing longer-term plans to enter Lake Vostok. As no one country has control over Antarctica, Petit and others are powerless to prevent the drilling. "There is no law to stop them doing what they want," he says.

Researchers familiar with the Russian programme say privately that the plans may have a political motive. They suggest that Lukin and his colleagues were forced to support a national project in order to get funding from the Russian government, as an international effort would have less prestige in the government's eyes. These experts hope that the Russian team will use the plan to generate funding but won't actually enter the lake. But Lukin insists that his team will sample the lake as planned. 